\title{
A comunicação de notícias ruins \\ e a pragmática da comunicação humana: 0 uso do cinema em at ividades de ensino/aprendizagem na educação médica
}

Ricardo Tapajós ${ }^{1}$

\author{
Introdução
}

A comunicação de notícias ruins é uma das tarefas mais difíceis encontrada pelos profissionais de saúde (Farrell et al., 2001; Mir, 2001; Vande-Kieft, 2001; Lomas et al., 2004). Ainda assim, é uma das mais freqüentes. Se esta tarefa é parte de sua profissão, seus currículos profissionais deveriam prepará-los para ela. Objetivos educacionais relativos a questões comunicacionais são pertinentes ao campo da Competência Comunicacional (Morse et al., 1992) e implicam treinamento focado nas técnicas e habilidades da comunicação humana (Dosanjh et al., 2001; Radziewicz \& Baile, 2001; Vande-Kieft, 2001; Lomas et al., 2004). De fato, tem havido relatos de vários programas de treinamento com diversas atividades instrucionais voltadas para preparar profissionais de saúde para a tarefa de comunicar notícias ruins (Abel et al., 2001; Farrell et al., 2001; Romm, 2002; Fujimori et al., 2003).

A Educação Médica, em especial, parece oferecer a seus alunos pouca preparação curricular formal para essa tarefa (Vande-Kieft, 2001). Atividades instrucionais que dizem respeito ao ensino-aprendizagem de tais objetivos são, por vezes, consideradas secundárias frente àquelas que abordam objetivos mais biomedicamente orientados, ou seja, que gozariam de um status "mais científico". Neste sentido, toda oportunidade deve ser usada para desenvolver e descrever atividades instrucionais que lidem com esses traços humanísticos, de maneira a encorajar sua inclusão consistente nos currículos médicos.

No entanto, o desenvolvimento de tais atividades de ensino-aprendizagem requer que o educador tenha em mente especificidades desses objetivos humanísticos. As atividades instrucionais tradicionais para o ensino-aprendizagem da comunicação de notícias ruins têm-se baseado em "conselhos práticos" e no conhecimento e na aplicação de protocolos e guidelines (Baile et al., 2000; Dosanjh et al., 2001; Vande-Kieft, 2001; Mueller, 2002; Barnett, 2004; Mir, 2004). Mas, diferentemente do conhecimento científico (que se proclama universal e reprodutível), esses traços humanísticos nem sempre seguem prescrições fixas ou receitas

${ }^{1}$ Médico Supervisor, Divisão de Clínica de Moléstias Infecciosas e Parasitárias, Hospital das Clínicas, Faculdade de Medicina, Universidade de São Paulo (FMUSP), São Paulo, SP. <ritapajos@uol.com.br> 
prontas. Há, provavelmente, mais do que um jeito adequado de contar notícias ruins a um paciente. Além disso, o que funciona para uma relação médico-paciente específica pode não funcionar para outra, na medida em que pacientes e médicos são humanamente diversos. Se não há receitas prontas para a comunicação de notícias ruins, as atividades instrucionais que abordam este assunto devem se valer de metodologias que possam dar conta dessa inerente diversidade de possibilidades.

Assim, essas atividades devem ter uma natureza dual. Por um lado, elas devem lidar com questões singulares, que podem diferir de uma relação médico-paciente específica para outra, e que induzem reflexão e reconhecimento de sentimentos, mais do que qualquer coisa. Por outro lado, essas atividades devem repousar sobre algum tipo de esqueleto ou arcabouço teórico que proveja princípios básicos que possam ser evocados e aplicados dentro de certos limites. Essas atividades instrucionais precisam, portanto, derivar conhecimentos de diferentes campos, integrando-os em uma mesma atividade. Uma forma de se lidar educacionalmente com questões singulares é usar as Artes (Pereira, 2000, 2005; Tapajós, 2003). Um arcabouço teórico para apoiar a instrução em Competência Comunicacional deve ser procurado entre as teorias da comunicação humana.

O objetivo deste texto é descrever e ilustrar possibilidades instrucionais em Competência Comunicacional abordando a comunicação de notícias ruins. Como base para essas possibilidades, propõe-se o uso conjunto das Artes (especificamente o Cinema) e da Teoria Comunicacional, que aborda a comunicação humana nos seus aspectos sintáticos, semânticos e pragmáticos.

\section{Cinema: seqüências fílmicas e sua interpretação}

Qualquer seqüência fílmica que retrate um médico comunicando notícias ruins para um paciente poderia ser usada em atividades de ensino-aprendizagem. Escolhemos duas seqüências do filme And the band played on (Spottiswoode, 1993), cujo título em português é E a vida continua.

Na primeira seqüência, Harold Jaffe, um médico (interpretado por Charles Smith) está sentado na sala de estar anexa ao quarto de uma paciente. Ela jaz reclinada no sofá, sua face pálida e aspecto doentio. As tomadas de câmera são clássicas: uma tomada geral para localizar os personagens, seguida de tomadas sucessivas de suas faces em plano/contraplano, enquanto dialogam. A paciente (Swoosie Kurtz) tinha se submetido a uma cirurgia cardíaca e estava experimentando complicações inexplicadas. O médico descobre que ela não tem ciência de seu diagnóstico (aids) e sente-se na obrigação de contar a ela. Ele lê alto um relatório de um dos médicos da paciente, endereçado para outro médico, contando-lhe que ela havia recebido sangue durante sua cirurgia e que, depois, descobriu-se que um dos doadores tinha aids. Um marido espantado debruça-se sobre o colo da esposa e chora desconsoladamente. A esposa coloca seus braços ao redor dele e tenta acalmá-lo, como a uma criança. Enquanto ele chora, a face dela está misteriosamente vazia.

Na segunda seqüência, Bill Kraus (Sir lan McKellen) recebe seu diagnóstico de aids. Ele está no consultório de um médico, esperando-o, enquanto conversa com um amigo. O doutor Marcus Conant (Richard Jenkins) entra pelo fundo do plano e comunica a notícia ruim de modo conciso: "sinto muito". A posição da câmera é tal que os personagens estão aglomerados em uma linha perpendicular à audiência. A reação do paciente é basicamente a mesma: o amigo perde o controle e o paciente tem de contê-lo, usando seus braços, com o mesmo gesto que a esposa havia feito. Na sua face, o mesmo vazio.

O que está sendo narrado (conteúdo) e a linguagem fílmica (forma) usada para narrá-lo são muito similares em ambas as seqüências. Em termos de seus conteúdos, as duas seqüências são sobre um médico comunicando uma notícia ruim a um paciente, que não exibe reações identificáveis. Os personagens que acompanham os pacientes são os que se exasperam e mostram reações intensas. Os pacientes assumem a posição de confortar seus 
acompanhantes, numa clara inversão de papéis. Em termos da linguagem fílmica, ambas as seqüências são construídas com a reiteração dos mesmos gestos e expressões. Por outro lado, a câmera diverge: na primeira seqüência, posiciona-se transversalmente aos personagens, e, na segunda, perpendicularmente a eles.

Vistas em conjunto, as seqüências parecem apontar que a forma como as noticias ruins são contadas não constitui a questão principal. Na primeira seqüência, o médico dá o diagnóstico de uma forma oblíqua: um primeiro médico lê um relatório de um segundo médico para um terceiro. O contar é multiplamente mediado, distanciado e técnico, conforme é, também, a narração da câmera. Na segunda seqüência, o médico é lacônico, mas afetivo. Não há nenhuma mediação última. A doença nem mesmo é nomeada. A posição da câmera abole a distância entre o profissional e o paciente, na medida em que os compacta visualmente. Entretanto, independentemente da forma do contar, em ambos os casos, a reação dos pacientes foi a mesma.

Essas seqüências parecem dizer que a importância das notícias ruins reside no que está sendo dito, e não na forma como isso é dito. A essência da notícia ruim pouco dependeria da forma como é comunicada, ou antes, não deixa de ser ruim, se é comunicada de maneiras diferentes. A natureza da notícia ruim precede a sua forma, de modo que seu impacto é pouco, senão nada modificado pelo fraseamento do médico. Essas hipóteses levantadas pela interpretação das seqüências necessitam de investigação.

Neste ponto, recomenda-se a referência a um arcabouço teórico mais inclusivo, que possa legitimamente locar a comunicação de notícias ruins dentro do contexto mais amplo da Comunicação Humana.

\section{Teoria comunicacional}

A comunicação de notícias ruins é uma forma de comunicação humana e, como tal, deve ser analisável sob o arcabouço teórico das teorias comunicacionais.

Uma dessas teorias entende que o estudo da Comunicação Humana compreende as mesmas três áreas (Sintática, Semântica e Pragmática) do estudo da Semiótica (Watzlawick et al., 1967). A Sintática aborda a transmissão da comunicação, ou seja, suas formas, canais e códigos. A Semântica lida com os significados que transitam na comunicação. A Pragmática aborda a comunicação na sua função relacional ou comportamental, ou seja, o que se faz com a comunicação e por meio dela (Watzlawick et al., 1967).

Sendo um fenômeno comunicacional, a comunicação de notícias ruins poderia, assim, ser abordada da perspectiva de qualquer uma dessas três áreas. Nas seqüências filmicas mencionadas, dois médicos comunicaram a notícia ruim de dois modos diferentes. Pode-se argumentar que cada um usou uma fórmula sintática diferente para o mesmo aspecto semântico (isto é, disseram a mesma coisa de jeitos diferentes). E, mesmo assim, produziram o mesmo resultado em seus pacientes (uma questão pragmática).

Abordar a questão da comunicação das notícias ruins com base nessas três diferentes perspectivas (semântica, sintática e pragmática), discutindo-as com os alunos, pode ser uma atividade de ensino-aprendizagem elucidativa no campo da Competência Comunicacional.

Em adição às seqüências filmicas, que servem como ponto de partida para a discussão, os alunos devem ser convidados a compartilhar as experiências que, porventura, tenham tido ao contar notícias ruins para seus pacientes, ou ao ver alguém fazê-lo. O professor deve ajudá-los a identificar aspectos sintáticos, semânticos e pragmáticos nas suas próprias comunicações médico-paciente. Alguns exemplos.

\section{A sintática da comunicação de notícias ruins}

Dois tópicos podem emergir na sintática da comunicação das notícias ruins: o uso de eufemismos médicos e o uso de linguagens não-verbais. 


\section{Eufemismos médicos}

Exemplos notáveis de confusão entre os níveis sintático e semântico da comunicação ocorrem com o uso de eufemismos médicos. Quando comunicam notícias ruins, os médicos podem sentir-se tentados a substituir palavras como "câncer" por outras como "neoplasia" ou "tumor". Nos discursos médicos, a infecção pelo HIV/aids, freqüentemente, é reduzida a sua condição de "doença crônica", assim comparável à hipertensão arterial. Esses eufemismos tentam amenizar a sintaxe das notícias ruins com a intenção de amenizar a sua semântica. Contudo, os aspectos semânticos continuam os mesmos: um câncer é um câncer, não importa qual a palavra usada para nomeá-lo. Estes aspectos podem ser enfatizados aos alunos, conforme apareçam. Uma boa forma de introduzir a questão para discussão é pedir aos alunos que se posicionem quanto à afirmação de que o uso médico dos eufemismos serve mais ao contador das noticias ruins (o médico), que ao receptor delas (o paciente).

\section{Linguagens não-verbais}

Perceber a existência de linguagens não-verbais é essencial à formação de futuros médicos. As comunicações podem usar linguagens digitais ou analógicas. A comunicação digital usa palavras e tem uma sintaxe lógica, complexa e poderosa para transmitir a mensagem. A comunicação analógica compreende toda comunicação não-verbal, incluindo a linguagem corporal, gestos, expressões, inflexões, e mesmo o silêncio (Watzlawick et al., 1967). O primeiro axioma da teoria comunicacional proclama a impossibilidade da não-comunicação (Watzlawick et al., 1967). Tudo tem valor de mensagem: atividade, inatividade, silêncio, palavras. Quando alguém permanece silencioso, está, de fato, se comunicando, ao deixar claro que não quer se comunicar.

Os alunos devem ser apresentados ao conceito de comunicação analógica e sua relevância: médicos devem ser habilidosos transmissores e receptores de comunicações analógicas na sua práxis médica diária.

\section{A semântica da comunicação de notícias ruins: morte e perda}

Em ambas as seqüências fílmicas, os pacientes não são consolados pelos acompanhantes. Ao contrário, são eles que, de fato, consolam seus acompanhantes, numa estranha inversão de papéis. Uma forma produtiva de desafiar os alunos é perguntar a eles por que e por quem eles acham que o marido chora (na primeira seqüência)..

Os alunos podem argumentar que ele chora porque antevê, para sua esposa, as possibilidades de sofrimento, decadência, exclusão social e toda a horda de horrores que costumavam acompanhar a morte por aids nessa época. Aparentemente, funciona como se a esposa tivesse recebido uma sentença de morte e ele estivesse reagindo a essa noticia. Mas as seqüências filmicas parecem querer dizer um pouco mais do que isto: a esposa não teria recebido uma sentença de morte, mas antes, uma sentença de morte já executada. Ela está, de alguma forma, morta, ou aspectos seus morreram em conseqüência da comunicação da má notícia. De fato, toda a linguagem fílmica referencia o espectador a um ambiente de velório: a paciente jaz numa superfície, sua face pálida e sem expressão. O marido reclina-se sobre a esposa e chora como um viúvo. Num funeral, são os vivos que choram seus mortos. Mortos, como nas seqüências, não choram.

Nessa perspectiva, a comunicação de notícias ruins deixa de representar a sentença de morte e passa a significar a morte consumada, a morte ela própria, a perda de algo. Porque lida com o significado, essa possibilidade interpretativa prioriza o aspecto semântico da comunicação. A seqüência parece dizer que, frente a notícias ruins, aspectos pertencentes ao paciente morrem, sejam seus planos, projetos, aspirações ou convicções. Essa paciente pode ter de abandonar a idéia de envelhecer ao lado do marido, ou de passar o próximo verão na Grécia, ou, ainda, de conhecer seus futuros netos.

Além de resgatar aspectos semânticos da comunicação de notícias ruins, esse exercício de interpretação pode possibilitar aos estudantes um tipo mais profundo de conhecimento, de cunho 
empático. Subtrai a comunicação de notícias ruins do rol de tarefas mecânicas cotidianas dos médicos e a reloca na história de vida de um paciente único e singular. Ajuda o estudante a considerar o outro lado, aquele em que está o paciente e sua subjetividade. Assim, incute-se, no aluno, flexibilidade de perspectiva.

\section{A pragmática da comunicação de notícias ruins}

\section{A inconsolabilidade da notícia ruim}

Nas seqüências filmicas, foram os pacientes que consolaram seus acompanhantes. Usando essas seqüências como base, o professor pode desafiar os estudantes a reescrevêlas, fazendo com que, nelas, os pacientes chorem e os acompanhantes os consolem. Esperase, dos estudantes, que escrevam uma ou duas linhas de texto como falas dos médicos.

A idéia é produzir um ambiente no qual os alunos possam sentir-se protegidos, na medida em que possam expressar seus pensamentos e ansiedades na terceira pessoa, colocando palavras e falas na boca dos personagens com quem simpatizaram ou com quem se comprometem em vários graus. Alguns alunos podem evocar situações que eles próprios experimentaram e podem desejar expressar-se mais corajosamente na primeira pessoa, contando experiências pessoais nas quais eles tentaram confortar e consolar seus pacientes.

A dificuldade da tarefa de escrever falas de consolo, logo, torna-se evidente para os alunos. Alguns deles irão sugerir que os médicos fiquem calados. Outros vão rechear seus discursos com sua própria ansiedade de dizer algo (ou qualquer coisa) a qualquer custo. Alguns alunos, provavelmente, vão incorrer em frases estereotipadas, que permitem leituras de subtextos, como "todos vão morrer um dia" ("mas eu realmente não acredito que eu vá morrer, já que sou médico"), ou, ainda, "estarei ao seu lado para o que você precisar" ("sempre relembrando a nós dois que é você quem está doente").

Esta discussão, enquanto atividade instrucional, possibilita focar vários assuntos pertinentes à Educação Médica. Os alunos podem perceber a impossibilidade de não comunicar: negar consolo é possível, mas negar comunicação não é (Watzlawick et al., 1967). Podem experimentar as possibilidades da comunicação analógica (como transmissores ou receptores de mensagens não-verbais); ou, ainda, investigar os limites da persona médica: podem os médicos chorar junto com seus pacientes? É permitido abraçá-los? Questões podem ser levantadas sobre os princípios éticos da autonomia e da beneficência: quanto deve ser dito ao paciente?

Esta discussão pode caminhar para direções bem diversas. Contudo, uma conclusão parece unânime, qual seja, que, nas seqüências, a tarefa de consolar os pacientes é árdua. Nesse ponto, o professor pode sugerir aos alunos que reconsiderem a idéia de reescrever as falas e passem a lidar com elas da maneira em que foram escritas: pacientes ficam silenciosos e acompanhantes choram. Uma desconstrução razoável deste papel invertido é a seguinte: médicos e acompanhantes nem tentam consolar porque as notícias ruins são intrinsecamente inconsoláveis.

A construção fílmica das seqüências reitera esta dimensão do impacto das noticias ruins e respeita sua natureza inconsolável. As seqüências, conforme foram escritas, respeitosamente recusam-se a produzir discursos médicos com más tentativas de consolo numa situação onde não há consolo. As seqüências calam os médicos e sua ansiedade de preencher os silêncios com discurso ocioso. Elas, conforme estão, asseguram a ausência de um discurso desqualificador.

\section{Desqualificação e discursos médicos desqualificadores}

Qualquer comunicação entre pessoas (o que inclui as relações médico-paciente) deve conformar-se a um de três padrões comunicacionais: confirmação, rejeição, ou desqualificação (Watzlawick et al., 1967). Confirmar é equivalente a dizer: "eu entendo o que você diz e concordo". Rejeitar é equivalente a dizer: "Eu entendo o que você diz e discordo". 
Ainda que possam parecer dolorosas, as rejeições implicam o conhecimento do que está sendo rejeitado, constituindo, assim, formas legítimas de comunicação. A desqualificação, ao contrário, implica comunicar-se de maneira a invalidar a comunicação própria e a alheia. Compreende (mas não é limitada a): declarações contraditórias, frases incompletas, interpretações espúrias, estilo obscuro, ou seja, a arte sutil de nada comunicar enquanto se diz algo (Watzlawick et al., 1967). A desqualificação introduz ruído na comunicação: parece uma resposta, mas nada responde. Ela sistematicamente opera na comunicação de pessoas que querem rapidamente evadir-se de situações que, de alguma forma, soam difíceis, quais sejam, aquelas nas quais essas pessoas preferem não comunicar, de modo a esquivar-se do compromisso inerente a qualquer tipo de comunicação. Já que a não-comunicação é impossível (primeiro axioma), usa-se a desqualificação. Com poucas exceções, confirmar ou rejeitar são formas saudáveis de comunicar-se, enquanto desqualificar tende a gerar incertezas.

O discurso desqualificador médico parece ser bem prevalente. "Todos vamos morrer um dia" pode ser uma desqualificação, na medida em que os pacientes podem não se encontrar ante uma dúvida existencial metafísica sobre a fugacidade da experiência humana no cosmo. Se os pacientes têm de lidar com a experiência singular da sua própria morte anunciada, dizer-lhes que "todos vamos morrer um dia", dificilmente, qualifica-se como consolo ou conforto.

As seqüências fílmicas parecem dizer que a comunicação de notícias ruins para pacientes é equivalente a colocar-lhes uma batata quente nas mãos. $O$ fato deve ser respeitado: 0 médico não pode argumentar que não é batata, nem quente. Ao se manterem calados nas seqüências, os personagens demonstram que entendem, confirmam e respeitam a natureza inconsolável e intrinsecamente trágica da notícia ruim.

Pode ser desejável introduzir os conceitos de confirmação, rejeição e desqualificação para os alunos. Já que não há receitas prontas de como comunicar notícias ruins, prover os alunos com um esqueleto conceitual de como a comunicação ocorre entre pessoas possibilita instrumentalizá-los na sua práxis e nas suas discussões sobre a relação médico-paciente. Pode ser oportuno ilustrar estes princípios ou, mesmo, aplicá-los a experiências anteriores dos alunos com seus pacientes e que queiram compartilhar com o grupo.

Em uma ocasião, um aluno relatou sua experiência. Numa enfermaria psiquiátrica, uma paciente, com uma condição maniforme, disse-Ihe que iria beijá-lo. Tomado de surpresa e inseguro em relação a como proceder, o aluno nem confirmou ("sim, você pode beijar-me na bochecha e eu receberei isto como sinal de sua afeição"), nem rejeitou a comunicação ("não, você não pode beijar-me porque sou seu médico e você sofre de uma condição que altera a forma como você expressa sua sexualidade"). Ele sorriu, deu-lhe um tapinha nos ombros, murmurou algo sobre como ela era engraçada e como eles iriam dar-se muito bem, e retirouse estrategicamente. A paciente seguiu-o e beijou-o, à sua revelia, e para seu espanto. $O$ estudante sentiu-se completamente invadido e teve sua pequena crise por não ter sabido lidar profissionalmente com a questão, quando ela se impôs. Este relato resultou em uma discussão particularmente fértil sobre a desqualificação, por meio da qual o aluno e seus pares formaram opiniões sobre o ocorrido e como ele poderia ter sido evitado.

Em outra situação, uma aluna relatou que, no começo de seus anos de internato, foi-lhe designada uma paciente soropositiva para HIV. Ambas tinham a mesma idade e compartilhavam aspectos socioculturais. A paciente piorou clinicamente e, um dia, perguntou, à queima-roupa, à aluna: "eu vou morrer?" A interna respondeu-lhe que ela não poderia saber se a paciente iria morrer ou não, mas que sua condição clínica estava de fato deteriorando, que ela não estava respondendo às intervenções e, sim, que ela corria o risco de morrer. A aluna aproveitou a situação para discutir com a paciente a conveniência e a propriedade de uma transferência para uma unidade de terapia intensiva (UTI). A paciente respondeu que tentaria todas as opções por causa de seu sistema de crença religiosa e que a equipe médica deveria realizar todo e qualquer esforço para manter a sua vida. Ela também requereu a 
presença de seus pais e de um pastor. Tomou, então, parte em uma pequena cerimônia religiosa, declarou-se pronta e foi transferida à UTI, onde faleceu após uma semana.

Ao recusar-se a desqualificar a comunicação da paciente, essa aluna foi protagonista de uma relação médico-paciente exemplar, na medida em que concedeu à paciente 0 direito de, informadamente, deliberar sobre a sua vida e seu corpo, preservando o princípio ético da autonomia. Esta paciente também pôde preparar-se para a própria morte de uma maneira muito apropriada, de acordo com seu sistema de crença.

\section{Conclusão}

A comunicação de notícias ruins é uma tarefa particularmente prevalente do trabalho médico. Alunos de medicina devem ser preparados para esta tarefa, com a ajuda de atividades instrucionais no campo da Competência Comunicacional. Tais atividades podem ser levadas a cabo com o uso das Artes Cinemáticas. Podem, também, ser informadas por um corpo de princípios teóricos derivados da Teoria Comunicacional. Como uma forma de comunicação humana, a comunicação de notícias ruins tem aspectos semânticos, sintáticos e pragmáticos. Apontá-los e usá-los no formato instrucional de discussão em pequenos grupos pode constituir rica experiência educacional.

\section{Referências}

ABEL, J.; DENNISON, S.; SENIOR-SMITH, G.; DOLLEY, T.; LOVETT, J.; CASSIDY, S. Breaking bad news - development of a hospital based training workshop. Lancet Oncol., v.2, n.6, p.380-4, 2001.

BAILE, W.K.; BUCKMAN, R.; LENZI, R.; GLOBER, G.; BEALE, E.A.; KUDELKA, A.P. SPIKES - a six-step protocol for delivering bad news: application to the patient with cancer. Oncologist., v.5, n.4, p.302-11, 2000.

BARNETT, M. A GP guide to breaking bad news. Practitioner, v.248, n.1659, p.392-4, 2004.

DOSANJH, S.; BARNES, J.; BHANARI, M. Barriers to breaking bad news among medical and surgical residents. Med. Educ., v.35, n.3, p.197-205, 2001.

FARRELL, M.; RYAN, S.; LANGRICK, B. Breaking bad news within a paediatric setting: an evaluation report of a collaborative education workshop to support health professionals. J. Adv. Nurs., v.36, n.6, p.765-75, 2001.

FUJIMORI, M.; OBA, A.; KOIKE, M.; OKAMURA, M.; AKIZUKI, N.; KAMIYA, M.; AKECHI, T.; SAKANO, Y.; UCHITOMI, Y. Communication skills training for Japanese oncologists on how to break bad news. J. Cancer Educ., v.18, n.4, p.194-201, 2003.

LOMAS, D.; TIMMINS, J.; HARLEY, B.; MATES, A. The development of best practice in breaking bad news to patients. Nurs. Times, v.100, n.15, p.28-30, 2004.

MIR, N.U. Breaking bad news: practical advice for busy doctors. Hosp. Med.,v.65, n.10, p.613-5, 2004.

MORSE, W.; BOTTOMS, M.S.; WASTLICK, L.A. Liberal and professional undergraduate nursing education: maintaining the connections. J. Prof. Nurs., v.8, n.5, p.282-8, 1992.

MUELLER, P.S. Breaking bad news to patients. The SPIKES approach can make this difficult task easier. Postgrad. Med., v.112, n.3, p.15-6, 2002.

PEREIRA, R.T.M.C. Teaching and learning in medical humanities: designing an elective course on HIV/ aids in the visual arts. 2000. Dissertation (Master of Health Professions Education) - Department of Medical Education, University of Illinois at Chicago, Chicago.

PEREIRA, R.T.M.C. O ensino da medicina através das humanidades médicas: análise do filme And the band played on e seu uso em atividades de ensino/aprendizagem em educação médica. 2005. Tese (Doutorado) - Departamento de Doenças Infecciosas e Parasitárias, Universidade de São Paulo, São Paulo. 
RADZIEWICZ, R.; BAILE, W.F. Communication skills: breaking bad news in the clinical setting. Oncol. Nurs. Forum, v.28, n.6, p.951-3, 2001.

ROMM, J. Breaking bad news in obstetrics and gynecology: educational conference for resident physicians. Arch. Women Ment. Health, v.5, n.4, p.177-9, 2002.

SPOTTISWOODE, R. And the band played on. Dirigido por Roger Spottiswoode. Nova York: HBO, 1993. 1 videocassete (140 min), VHS, son., color.

TAPAJÓS, R. HIV/AIDS in the visual arts: applying discipline-based art education (DBAE) to medical humanities.

Med. Educ., v. 37, p.563-70, 2003.

VANDE-KIEFT, G.K. Breaking bad news. Am. Fam. Phys., v.64, n.12, p.1975-8, 2001.

WATZLAWICK, P.; BAVELAS, J.B; JACKON, D.D. Pragmatics of human communication: a study of interactional patterns, pathologies and paradoxes. New York: W. W. Norton \& Company, 1967.

Atividades de ensino-aprendizagem no campo da Competência Comunicacional (tais como aquelas que dizem respeito à comunicação de notícias ruins para pacientes) podem usar as Artes Cinemáticas e ser informadas por um corpo de princípios teóricos derivados da Teoria Comunicacional (que estuda a comunicação humana nos seus aspectos sintáticos, semânticos e pragmáticos). Tópicos na sintática da comunicação de notícias ruins incluem o uso de eufemismos médicos e linguagens não-verbais. A semântica das notícias ruins foca naquilo que está sendo comunicado, e não em como está sendo comunicado. Aspectos pragmáticos são discutidos aqui com mais detalhes e envolvem a desqualificação e os discursos médicos desqualificadores.

PALAVRAS-CHAVE: educação médica. humanidades. teoria comunicacional. artes cinemáticas.

Breaking bad news and the pragmatics of human communication: the use of cinema in teaching/learning activities in medical education

Teaching/learning activities in the field of Communication Competence (such as those that address breaking bad news to patients) can resort to the Cinematic Arts and draw information from a body of theoretical principles found in Communicational Theory (which studies human communication in its syntactical, semantic and pragmatic aspects). Topics in the Syntactics of breaking bad news include the use of euphemisms and non-verbal language. The Semantics of bad news focuses on what is communicated, rather than on how one communicates it. Pragmatic aspects are discussed in more detail and involve disqualification and disqualifying medical discourses.

KEY WORDS: medical education. humanities. communication. films.

La comunicación de malas noticias y la pragmática de la comunicación humana: el uso del cine en actividades de enseñanza/aprendizaje en la educación médica

Las actividades de enseñanza/aprendizaje en el campo de la Competencia Comunicacional (como las que tratan de la comunicación de malas noticias a los pacientes) pueden utilizar las Artes Cinemáticas y pueden ser informadas por un cuerpo de principios teóricos derivados de la Teoría Comunicacional (que estudia la comunicación humana en sus aspectos sintácticos, semánticos y pragmáticos). Los tópicos en la sintáctica de la comunicación de malas noticias incluyen el uso de los eufemismos médicos y del lenguaje no verbal. La semántica de las noticias malas enfoca lo que se está diciendo y no cómo se lo dice. Los aspectos pragmáticos son discutidos con más detalles y envuelven la descalificación y los discursos médicos descalificadores.

PALABRAS CLAVE: educación médica. humanidades. películas. comunicación. 